\title{
Prestin and the Dynamic Stiffness of Cochlear Outer Hair Cells
}

\author{
David Z. Z. He, ${ }^{1,2}$ Shuping Jia, ${ }^{1}$ and Peter Dallos ${ }^{3}$ \\ ${ }^{1}$ Department of Biomedical Sciences, Creighton University Medical School, Omaha, Nebraska 68175, ${ }^{2}$ Hair Cell Biophysics Laboratory, Boys Town National \\ Research Hospital, Omaha, Nebraska 68131, and ${ }^{3}$ Auditory Physiology Laboratory, Departments of Neurobiology and Physiology and Communication \\ Sciences and Disorders, Northwestern University, Evanston, Illinois 60208
}

The outer hair cell $(\mathrm{OHC})$ lateral wall is a unique trilaminate structure consisting of the plasma membrane, the cortical lattice, and subsurface cisternae. $\mathrm{OHCs}$ are capable of altering their length in response to transmembrane voltage change. This so-called electromotile response is presumed to result from conformational changes of membrane-bound protein molecules, named prestin. $\mathrm{OHC}$ motility is accompanied by axial stiffness changes when the membrane potential of the cell is altered. During length changes, intracellular anions (mainly $\mathrm{Cl}^{-}$) act as extrinsic voltage sensors. In this study, we inquired whether the motor proteins are responsible for the voltagedependent axial stiffness of $\mathrm{OHCs}$, and whether $\mathrm{ACh}$, the neurotransmitter of efferent neurons, modulates the stiffness of the cortical lattice and/or the stiffness of the motor protein. The experiments were done on isolated guinea pig OHCs in the whole-cell voltage-clamp mode. Axial stiffness was determined by loading a fiber of known stiffness onto the apical surface of the cells. Voltage-dependent stiffness and cell motility disappeared, and the axial stiffness of the cells significantly decreased after removal of intracellular $\mathrm{Cl}^{-}$. The result suggests that the stiffness of the motor protein is a major contributor to the global axial stiffness of OHCs. ACh was found to affect both the motor protein and other lateral wall stiffness components.

Key words: cochlea; outer hair cells; axial stiffness; prestin; motility; ACh; guinea pigs

\section{Introduction}

Hearing sensitivity in mammals is enhanced by $>40 \mathrm{~dB}$ by mechanical amplification generated by length changes (termed electromotility) of outer hair cells (OHCs) (Brownell et al., 1985; Kachar et al., 1986; Ashmore, 1987; Liberman et al., 2002). OHCs possess an elaborate and highly structured cortical network of actin and spectrin filaments sandwiched between the plasma membrane and concentric layers of endoplasmic reticula, known as the subsurface cisternae (for review, see Holley, 1996). The density of integral membrane proteins in the lateral plasma membrane is also unusually high, $\sim 5200 / \mu \mathrm{m}^{2}$ (Forge, 1991). These $\sim 10$-nm-diameter molecules are assumed to be the motor proteins, or multimers of the motor proteins, whose concerted voltage-dependent conformational change is funneled into somatic length change of the cell via the cortical network (Holley and Ashmore, 1988; Kalinec et al., 1992). Recently, a gene named Prestin that codes for the motor protein prestin has been identified (Zheng et al., 2000).

Under the influence of the turgor pressure of the cell, the plasma membrane, the cortical lattice, and the subsurface cisternae potentially contribute to the global axial stiffness of OHCs. The static axial stiffness of OHCs has been measured previously (Holley and Ashmore, 1988; Zenner et al., 1992; Gitter et al.,

\footnotetext{
Received July 14, 2003; revised Aug. 20, 2003; accepted Aug. 22, 2003.

This work was supported by National Institutes of Health Grants R01 DC 04696 (D.Z.Z.H.) and R01 DC 00089 (P.D.) from the National Institute of Deafness and Other Communication Disorders.

Correspondence should be addressed to David Z.Z. He, Department of Biomedical Sciences, Creighton University, 2500 California Plaza, Omaha, NE 68175. E-mail: hed@creighton.edu.

Copyright $\odot 2003$ Society for Neuroscience $\quad$ 0270-6474/03/239089-08\$15.00/0
}

1993; Hallworth, 1995; Iwasa and Adachi, 1997; Ulfendahl et al., 1998). Static stiffness can also be manipulated by various means (Hallworth, 1997). Axial stiffness and electromotile forces were reduced by $65 \%$ when $5 \mathrm{~mm}$ salicylate was applied to the cell (Russell and Schauz, 1995). Dallos et al. (1997) demonstrated that delivery of the efferent neurotransmitter of the OHC, acetylcholine (ACh), to the synaptic pole of the cell also decreased the axial stiffness.

Although the axial stiffness of OHCs has been studied, relative stiffness of the lateral wall components is still poorly understood. Some studies suggest that the plasma membrane appears to be relatively stiff and may be the dominant contributor to the axial stiffness of intact cells (Holley and Ashmore, 1988; Tolomeo et al., 1996), whereas a study by Oghalai et al. (1998) indicates that the cortical lattice may account for $\sim 70 \%$ of the axial stiffness. Adachi and Iwasa (1997) also showed that when diamide was applied to the cells, the axial stiffness of OHCs was reduced by $65 \%$. Diamide presumably only affects spectrin in the cortical lattice. We previously reported that OHCs also possessed a dynamic stiffness component, that is, they changed their axial stiffness when their membrane potential was altered (He and Dallos, 1999).

It has been demonstrated that bound intracellular anions act as extrinsic voltage sensors during length change and that removal of intracellular anions, specifically chloride, abolishes both motility and its electrophysiological signature, nonlinear capacitance (Oliver et al., 2001). The present study aims to determine whether removal of intracellular chloride also abolishes voltagedependent stiffness. If the voltage-dependent stiffness is indeed eliminated when somatic motility is abolished, then it is possible 
to separate the voltage-dependent stiffness from the global stiffness of the cells. This would allow us to study two other important issues. First, it would permit the determination of contributions caused by voltage-dependent stiffness, attributable to the motor proteins, to the overall axial stiffness of the cell. Second, it would allow us to examine whether $\mathrm{ACh}$, the efferent neurotransmitter, demonstrated to alter both OHC motility and stiffness (Dallos et al., 1997), modulates the stiffness of the motor protein and/or the stiffness of the cortical lattice.

\section{Materials and Methods}

Care and use of the animals in this study were approved by the National Institutes of Health and the Animal Care and Use Committee of the Boys Town National Research Hospital.

Hair cell preparation. Adult guinea pigs (weight range, 150-300 gm) were decapitated after intraperitoneal injection of a lethal dose of sodium pentobarbital (200 mg/kg, i.p.). The cochleae were dissected and kept in cold tissue culture medium (Leibovitz's L-15). The organ of Corti was isolated from third and fourth turns of the cochlea. After brief enzymatic digestion ( $1 \mathrm{mg} / \mathrm{ml}$ type IV collagenase; Sigma, St. Louis, MO), cells were transferred to small plastic chambers filled with enzyme-free culture medium. Solitary cells were obtained after gentle trituration. The normal extracellular medium was Leibovitz's L-15 (Invitrogen, Gaithersburg, MD ), supplemented with 10 mM HEPES and adjusted to $\mathrm{pH} 7.35,300-$ 310 mOsm (inorganic components in mM: $\mathrm{NaCl} 136, \mathrm{NaH}_{2} \mathrm{PO}_{4} 5.8, \mathrm{KCl}$ 5.4, $\mathrm{CaCl}_{2} 1.3, \mathrm{MgCl}_{2} 0.9$, and $\mathrm{MgSO}_{4}$ 0.4). All experiments were performed at room temperature $\left(22 \pm 2^{\circ} \mathrm{C}\right)$.

Whole-cell voltage-clamp recordings. Whole-cell voltage-clamp recordings were performed on a Nikon inverted microscope and with an Axopatch 200A amplifier (Axon Instruments, Union City, CA). The patch pipette with the headstage was held by a Narishige 3D micromanipulator (MHW-3; Narishige, Tokyo, Japan). Whole-cell voltage-clamp tight-seal recordings were established as described by Ashmore (1987) for guinea pig OHCs. The patch electrodes were pulled from $1.5 \mathrm{~mm}$ glass capillaries (A-M Systems, Inc., Carlsborg, WA) using a Flaming-Brown micropipette puller (model P-87; Sutter Instruments, Novato, CA). Recording pipettes had open tip resistances of 3-4 M $\Omega$ and were filled with an internal solution that consisted of (in mM): $150 \mathrm{KCl}, 2 \mathrm{MgCl}_{2}, 1 \mathrm{EGTA}$, and $10 \mathrm{HEPES}$. $\mathrm{KOH}$ was used to adjust $\mathrm{pH}$ to 7.3. To replace the intracellular $\mathrm{Cl}^{-}$, the following intracellular medium was used: $150 \mathrm{~mm}$ Na-pentane-sulfonate, 10 HEPES, and 1 mM EGTA. The access resistance typically ranged from 8 to $12 \mathrm{M} \Omega$ after the whole-cell recording configuration was established. Approximately $70 \%$ of the series resistance was compensated.

Stiffness measurement. Glass fibers were pulled from $1.5 \mathrm{~mm}$ glass tubing by a microforge (Stoelting, Chicago, IL). The tapered tip of a fiber was usually $6-8 \mathrm{~mm}$ in length and $3-4 \mu \mathrm{m}$ in diameter. With these dimensions, it was expected that the stiffness at the tip of the fiber would be close to that of the cells. The glass fiber was attached to an electrical piezo actuator, which was mounted on a three-dimensional Narishige micromanipulator. The experimental arrangement for measurements of stiffness changes under whole-cell voltage-clamp condition is illustrated in Figure 1. Most of the recordings were made from healthy looking OHCs that were in a cluster (Fig. 1), although some recordings were made from isolated OHCs when the effects of ACh on motility and stiffness were examined. This strategy was used because cells were more mechanically stable in a cluster and had less of a tendency to turn or rotate when the fiber was loaded onto them. This stability also helped to prevent loss of the seal during loading by the fiber and the subsequent measurement. The tip of the glass fiber was brought against the surface of the cuticular plate of the cells so that the cell and fiber were approximately perpendicular. The fiber was placed transverse to the long axis of the $\mathrm{OHC}$ in such a way that the lateral motions of the fiber would compress or relax the cell. It was important that the fiber compress the cell somewhat before setting the fiber or cell into motion because, if it were not preloaded, the fiber could be detached from the cell during the contraction of the cell. Because an OHC can shorten as much as $5 \%$ of its initial length after the intracellular $\mathrm{Cl}^{-}$is eliminated (D. He and $\mathrm{P}$. Dallos, unpublished observation), readjustment of the attachment of the

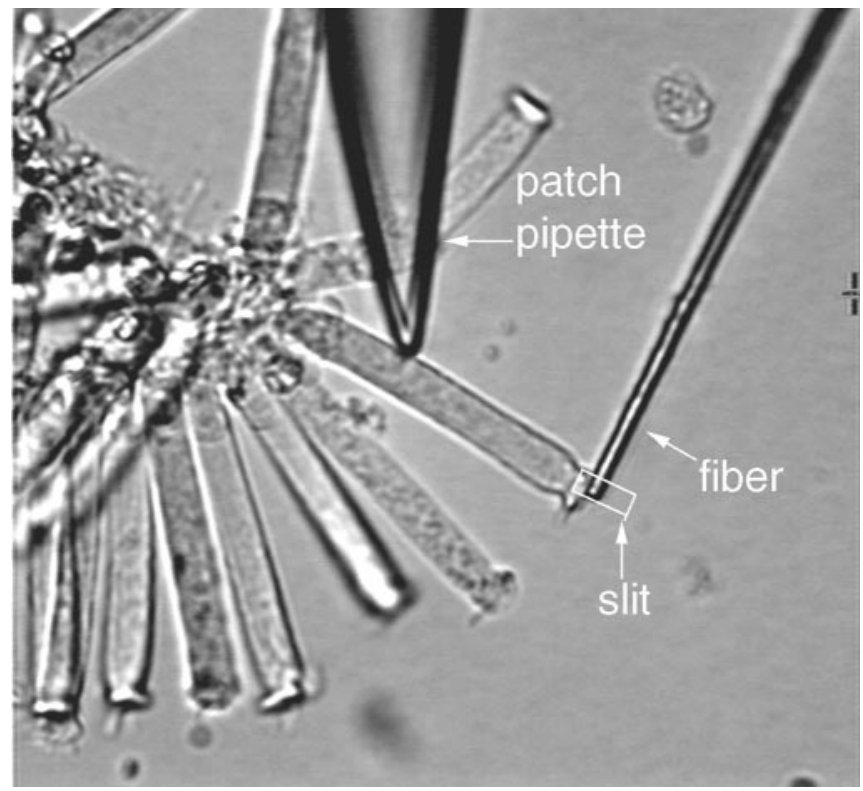

Figure 1. Illustration of recording $\mathrm{OHC}$ somatic motility and fiber-driven length change under whole-cell voltage-clamp condition. A glass fiber with known stiffness is brought against the surface of the cuticular plate of the cell. After the fiber is loaded onto the cell, a sinusoidal voltage command is applied to a piezoelectric driver, to which the fiber is attached. The motion of the fiber compresses or relaxes the cell. The amplitude of the fiber-driven motion is determined by the stiffness of the fiber and the cell. Only the proximal tip of the fiber is shown; it is connected at its distal end to a piezo bimorph. The motion of the fiber and/or the cell is measured by projecting the image of the junction between the fiber-cell complex onto a photodiode though a rectangular slit. The photocurrent response is calibrated to displacement units by moving the slit by a fixed distance.

fiber to the cell was made before measurement was taken after the intracellular $\mathrm{Cl}^{-}$was exchanged. A detailed discussion of loading the fiber onto the cell and the effects caused by loading was given elsewhere ( $\mathrm{He}$ and Dallos, 2000). Loaded motility, free-fiber motion, and a combination of motility and fiber-driven cell motion were measured. In most cases, the cells were held at $-70 \mathrm{mV}$, and voltage steps with a duration of $100 \mathrm{msec}$ were delivered to the cells to evoke motility. Sinusoidal voltage bursts (frequency: $100 \mathrm{~Hz}$ ) were applied to the bimorph to drive the fiber motion. Stiffness of glass fibers was calibrated by the "string instrument" method, described in detail by Zwislocki and Cefaratti (1989). The stiffness of the fibers used in this experimental series ranged from 2.6 to 4.8 $\mathrm{mN} / \mathrm{m}$. The axial stiffness $\left(K_{\mathrm{c}}\right)$ of the cell was measured by comparing the free movement $\left(L_{\mathrm{f}}\right)$ of the tip of the fiber of known stiffness $\left(k_{\mathrm{f}}\right)$ with the loaded movement of the tip $\left(L_{c}\right)$ after it was rested against the surface of the cuticular plate, where:

$$
K_{\mathrm{c}}=k_{\mathrm{f}}\left(L_{\mathrm{f}}-L_{\mathrm{c}}\right) / L_{\mathrm{c}} .
$$

Displacement measurement. Cell motility and fiber motion were measured by a photodiode system. The magnified image of the ciliated pole of the cell and the fiber or the fiber alone (loaded vs unloaded) was projected onto the photodiode through a rectangular slit. The position of the slit in front of the photodiode was adjustable so that the image of the object could always be projected onto the photodiode without moving the cell or the fiber. The position of the image in the slit was monitored by a video camera behind it. The image of the entire cell was also obtained by a second video camera and displayed throughout the experiment. Cell-length changes or fiber displacements were measured by changes in the current of the photodiode. The photocurrent response was calibrated to displacement units by moving the slit by a fixed distance $(0.5 \mu \mathrm{m})$ with the image of the cell (or fiber) in front of the photodiode at the beginning of each trial. The 
photodiode-measuring system had a resolution of $\sim 15 \mathrm{~nm}$ after averaging 10 presentations and low-pass filtering (set at $250 \mathrm{~Hz}$ ). The $3 \mathrm{~dB}$ cutoff frequency of the measuring system was at 1100 $\mathrm{Hz}$. Ten averages were usually preset for each trial. Several parameters were measured. These were "unloaded motility," the measurement of the electrically induced motile displacement response of the cells without loading by the fiber; "free-fiber" motion, the displacement of the tip of the fiber when driven by the bimorph but not loaded by the cell; and "loaded response," the joint displacement of the junction between cell and fiber after loading. In this last category, distinction is made among responses obtained (1) when only the fiber was actively moved and the cell served as a load ("fiber-driven response"), and (2) when both electromotility and fiber motion were induced. The last response type provided the fundamental data for this paper.

ACh application. ACh was delivered by pressure ejection from a micropipette with tip diameter of 3-4 $\mu \mathrm{m}$ positioned $20 \mu \mathrm{m}$ from the synaptic pole of the cell. The tip of the micropipette was siliconized to reduce capillary action. The duration and strength of the pressure pulse were controlled by a pneumatic micropump (model PV820; WPI, Inc., Sarasota, FL), which, in turn, was controlled by the computer. The half-activating concentration for ACh receptors in OHCs is $20-25 \mu \mathrm{M}$, and the response is maximal at $100 \mu \mathrm{M}$ (Elgoyhen et al., 1994; Dallos et al., 1997). In this study, $50 \mu \mathrm{M}$ ACh was used. The ACh solution was freshly prepared before each experiment.

\section{Results}

\section{Motility and voltage-dependent stiffness}

The voltage dependence of axial stiffness change was examined in previous studies (He and Dallos, 1999, 2000). To minimize damage by repetitive and large-voltage stimulation for a relatively long period of time during recordings, only two voltage steps (50 $\mathrm{mV}$ in step size) were used to evoke motility and stiffness changes in the depolarizing and hyperpolarizing directions from a holding potential of $-70 \mathrm{mV}$. Five cells were examined for voltagedependent stiffness changes under whole-cell voltage-clamp condition with normal internal solution. Motility was first measured without loading the cell with a fiber. Membrane potential was stepped to -120 and $-20 \mathrm{mV}$ from a holding potential of -70 $\mathrm{mV}$ to evoke motility. Robust motility (Fig. 2A) was seen when the patch pipette filled with normal internal solution (including $150 \mathrm{mM} \mathrm{Cl}^{-}$) was used. After free motility was measured, a glass fiber with known stiffness was loaded onto the surface of the cuticular plate of the cell. The base of the fiber was driven sinusoidally at $100 \mathrm{~Hz}$, whereas the $\mathrm{OHC}$ was electrically stimulated via the patch pipette with $50 \mathrm{mV}$ voltage steps $(-120$ and -20 $\mathrm{mV}$ ) around the holding potential of $-70 \mathrm{mV}$. The fiber-driven response with motility was measured. During the presentation of DC step voltages, one sees a DC shift in the baseline, representing the electromotile response of the cell to the voltage steps (Fig. $2 \mathrm{~B}$ ). It is also seen that during the steps the amplitude of the 100 $\mathrm{Hz}$ fiber motion is altered. Hyperpolarization produces cell elongation and a decrease in the amplitude of fiber motion. Conversely, depolarization of the cell produces contraction and an increase in fiber amplitude (Fig. 2B). The change in AC response suggests that the stiffness of the cell depends on the transmembrane voltage; hyperpolarization increases the axial stiffness of the cell, whereas depolarization decreases the stiffness. This voltage-dependent stiffness change of $\mathrm{OHCs}$ has been described previously (He and Dallos, 1999, 2000).

To examine the voltage-dependent stiffness change and its relation to electromotility, seven additional cells were used under
$150 \mathrm{mM} \mathrm{Cl}^{-}$ $150 \mathrm{mM}$ pentane-sulfonate-
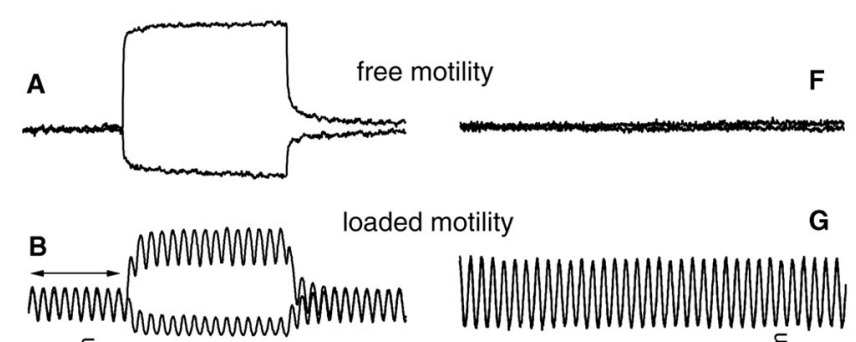

C|유

free fiber motion
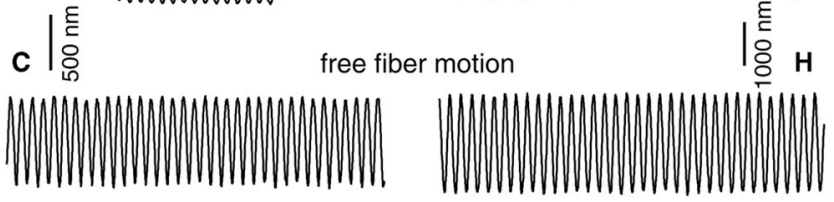

D

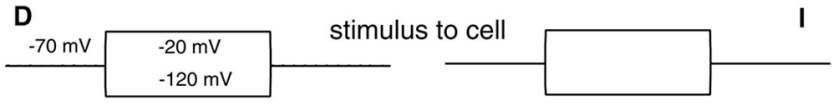

$\mathbf{E}$

stimulus to fiber

$\mathbf{J}$
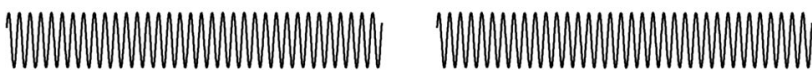

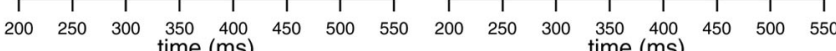

Figure 2. Examples of somatic motility and voltage-dependent stiffness changes obtained from two $\mathrm{OHCs}$ with (left panels) and without intracellular $\mathrm{Cl}^{-}$(right panels). $A$, Length changes measured from a $75 \mu \mathrm{m} \mathrm{OHC}$ with no load. The cell was held at $-70 \mathrm{mV}$ under whole-cell voltage-clamp condition. Length changes were evoked by the voltage commands whose waveforms are shown in $D$. The patch pipette contained normal internal solution with $150 \mathrm{~mm} \mathrm{Cl}^{-}$(see Materials and Methods). Robust motility was observed. In this and all subsequent figures, upward deflections represent depolarization (cell contraction). B, Loaded-fiber response with motility evoked. A fiber with known stiffness was loaded onto the cuticular plate of the cell (same cell as shown in A) to set the cell into axial motion (compress or relax the cell). The fiber was driven by sinusoidal voltage commands whose waveform is shown in $E$. The cell was held at $-70 \mathrm{mV}$, and electromotility was evoked by the voltage commands shown in $D$. Voltage-dependent stiffness change was observed. The stiffness change is reflected by changes of the amplitude of the loaded-fiber motion during motility; the amplitude increased during cell contraction, and decreased during elongation with reference to the baseline (indicated by arrows). C, Free fiber motion without loading by the cell. Motion of the fiber was driven by voltage commands whose waveform is shown in E. Comparing the amplitude of unloaded (shown in $C$ ) and loaded fiber motion (baseline response marked by arrows in $B$ ), one notices that the motion of the fiber was significantly reduced after loading by the cell. The static axial stiffness of the cell can be calculated based on the equation given in Materials and Methods. The stiffness of the fiber was $3.1 \mathrm{mN} / \mathrm{m}$. The axial stiffness of this cell was $4.2 \mathrm{mN} / \mathrm{m}$. D, I, Voltage commands applied to the cell. $E, J, 100 \mathrm{~Hz}$ sinusoidal voltage commands applied to the fiber. $F$, Length change response measured from an $80 \mu \mathrm{m} \mathrm{OHC}$ after intracellular $\mathrm{Cl}^{-}$was replaced by $150 \mathrm{~mm}$ pentane sulfonate in the patch pipette. The cell was held at $-70 \mathrm{mV}$, and voltage commands (shown in /) were applied to the cell. No motility was observed. G, Loaded-fiber responses to the voltage commands with $150 \mathrm{~mm}$ pentane sulfonate in the patch pipette to replace intracellular $\mathrm{Cl}^{-}$. There are two traces overlapping in $G$ that are responses to voltage steps of -120 and $-20 \mathrm{mV}$. Note that voltage-dependent stiffness change also disappeared when motility was eliminated.

whole-cell voltage-clamp condition with patch pipettes filled with $150 \mathrm{~mm}$ pentane sulfonate to replace the intracellular $\mathrm{Cl}^{-}$. We have shown before that replacement of intracellular anions with pentane sulfonate eliminates electromotility (Oliver et al., 2001). The same experimental paradigm was used in an attempt to obtain unloaded motile responses and fiber-driven responses while delivering electrical signals that in normal cells elicit motility. The responses obtained from one representative $\mathrm{OHC}$ at $2 \mathrm{~min}$ after rupturing the cell are shown in the right panels of Figure 2. As shown in Figure $2 \mathrm{~F}$, no motility was observed when the intracellular $\mathrm{Cl}^{-}$ 
was replaced by pentane sulfonate. This is consistent with the conclusion that intracellular $\mathrm{Cl}^{-}$, attached to a binding site, is the voltage sensor of the motor protein (Oliver et al., 2001). Importantly, when the motility was eliminated, the voltage-dependent stiffness change also disappeared. This is reflected by the lack of modulation of the magnitude of fiber-driven motion during depolarization and hyperpolarization of the cell (Fig. 2G).

\section{Contribution of voltage-dependent stiffness to the overall axial stiffness}

The outer hair cell lateral wall consists of the plasma membrane, the cortical lattice (CL), and the subsurface cisternae (SC). Because the motor proteins constitute $\sim 70 \%$ of the surface area of the plasma membrane, it is assumed that the motor proteins would significantly contribute to the stiffness of the plasma membrane. To determine whether it is the plasma membrane or the CL-SC complex that is primarily responsible for lateral wall stiffness, changes in axial stiffness of OHCs were determined before and after the voltage-dependent motility was eliminated. This was done by comparing the stiffness of an OHC before and after its intracellular $\mathrm{Cl}^{-}$was removed. Control experiments with normal internal solution, having $150 \mathrm{~mm} \mathrm{Cl}^{-}$in the patch pipettes, were also done with the same paradigm to make sure that any stiffness changes seen were not attributable to the change in turgor pressure after rupturing the cells. Forty OHCs were used for this series of experiments. Examples of the responses obtained from the control (with $\mathrm{Cl}^{-}$) and experimental (without $\mathrm{Cl}^{-}$) groups are presented in Figure 3. The fiber-driven response was measured before the membrane of the cell was ruptured, and this initial measurement served as a reference to determine the stiffness changes afterward (Fig. $3 A, D$ ). After the membrane was ruptured, two voltage steps $(-120$ and $-20 \mathrm{mV})$ from a holding potential of $-70 \mathrm{mV}$ were applied to the cell to evoke motility. The fiber-driven response was re-measured. The measurements were taken at $2 \mathrm{~min}$ after rupturing the cells. When the patch pipette was filled with $150 \mathrm{~mm} \mathrm{Cl}^{-}$, robust motility was observed (Fig. 3B, DC shift). Voltage-dependent stiffness change was also evident; note that the amplitude of fiber-driven motion was altered during length-change. The amplitude of baseline response (Fig. 3B, arrows) was reduced by $\sim 11 \%$ compared with the response before the membrane was ruptured. This apparent underlying stiffness change is likely caused by the change in membrane potentials before and after rupturing the cells (see below). In contrast, when the cells were ruptured by patch pipettes filled with $150 \mathrm{~mm}$ pentane sulfonate, motility and voltage-dependent stiffness disappeared (Fig. 3E). Significantly, the amplitude of fiber-driven response after rupturing was much greater than the reference response (Fig. 3D) measured before rupturing the membrane of the cell. The increased fiber response was not attributable to the shortening of the cell caused by the depletion of intracellular $\mathrm{Cl}^{-}$, which could result in detachment of the fiber to the cell or the loose contact between the fiber and the cell, because proper adjustment of the fiber was made to compensate for the static contraction of the cell. With the known stiffness of the fibers and the amplitude of fiber-driven response and free-fiber motion, we computed the stiffness changes for both groups of cells. Twenty cells were measured in each group, and the results are summarized in Figure 4.

In Figure 4, changes in axial stiffness with and without the influence of voltage-dependent stiffness from the motor protein are shown. The stiffness measured after the membrane of the cell was ruptured is plotted against the initial stiffness (before rupture) for both groups. In the left panels, the data are obtained

\section{$150 \mathrm{mM} \mathrm{Cl}^{-} \quad 150 \mathrm{mM}$ pentane-sulfonate}
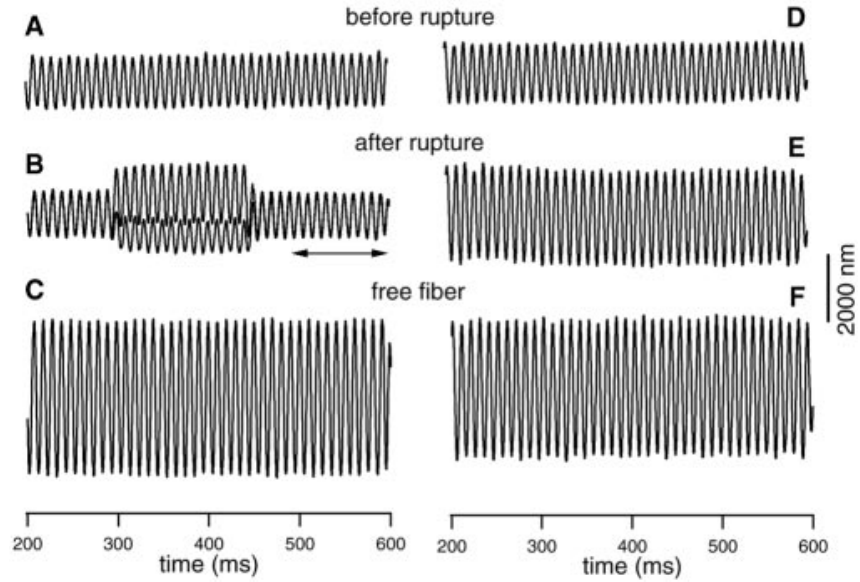

Figure 3. Examples of loaded fiber responses obtained from two cells with (left panels) and without intracellular $\mathrm{Cl}^{-}$(right panels). A, D, Loaded fiber motion measured before the membrane of the cells was ruptured. In both cases, the cell was held by a patch pipette. The fiber was loaded onto the cuticular plate. The fiber motion was driven by a piezo biomorph. B, E, Loaded fiber motion measured after the membrane of the cells was ruptured. The cell was held at -70 $\mathrm{mV}$, and step stimuli were applied to the cell to evoke motility. The patch pipette was either filled with normal internal media with $150 \mathrm{~mm} \mathrm{KCl}$ (for $B$ ) or $150 \mathrm{~mm}$ sodium pentane sulfonate (E). As shown in $B$, the amplitude of the loaded-fiber motion was altered during motility, reflecting the voltage-dependent stiffness change of the cell. Note that the loaded fiber motion was $\sim 11 \%$ smaller after the membrane of the cell was ruptured (the baseline response marked by arrows in $B$ ), in comparison with the response before rupturing $(A)$. For the response shown in $E$, no voltage-dependent stiffness change was observed. Also, the amplitude of the loaded fiber motion increased by $\sim 50 \%$ after the membrane of the cells was ruptured and intracellular $\mathrm{Cl}^{-}$was replaced by pentane sulfonate. Note that there are two traces overlapping in E.C, F, Unloaded fiber motion. The static stiffness of the cells was computed based on the amplitudes of the loaded fiber motion $(B, E)$ and free fiber motion $(C, F)$, and the stiffness of the fiber. The stiffness for the two cells is $4.5 \mathrm{mN} / \mathrm{m}$ (left panels; fiber stiffness: $3.1 \mathrm{mN} / \mathrm{m}$ ) and $4.3 \mathrm{mN} / \mathrm{m}$ (right panels, fiber stiffness: $3.1 \mathrm{mN} / \mathrm{m}$ ), respectively.
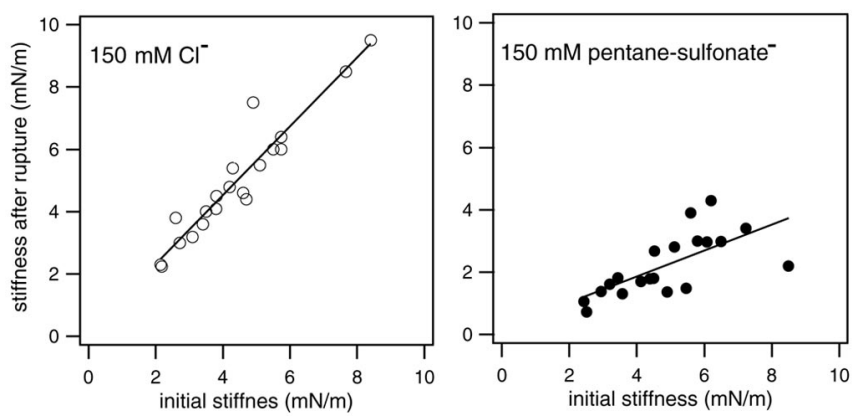

Figure 4. Changes in axial stiffness with and without the influence of active motor proteins. The stiffness measured after the membrane of the cells was ruptured is plotted against the initial stiffness (before rupture) for both groups. In the left panel, the data were obtained from cells with $150 \mathrm{mM} \mathrm{Cl}^{-}$in the patch pipette. Note that the stiffness after rupture is greater than the initial stiffness of the cells. The mean increase is $11 \%$, with SD of $10 \%(n=20)$. In the right panel, the data were collected from the cells whose intracellular $\mathrm{Cl}^{-}$was replaced by pentane sulfonate. The stiffness after rupturing the membrane of the cells was reduced significantly with reference to the initial stiffness in this group. The mean stiffness reduction is $54 \%$, with SD of $12 \%(n=20)$. Linear regression lines are fitted to both sets of data. Their slopes are 1.11 and 0.42 , respectively.

from cells that were dialyzed with a solution containing $150 \mathrm{mM}$ Cl. As shown above (i.e., Fig. 3), motility and voltage-dependent stiffness were observed in this group of cells. The stiffness of the cells after rupture was greater than the initial stiffness of the cells (the mean change was $11 \%$, with SD of $10 \%$ in 20 cells). The 


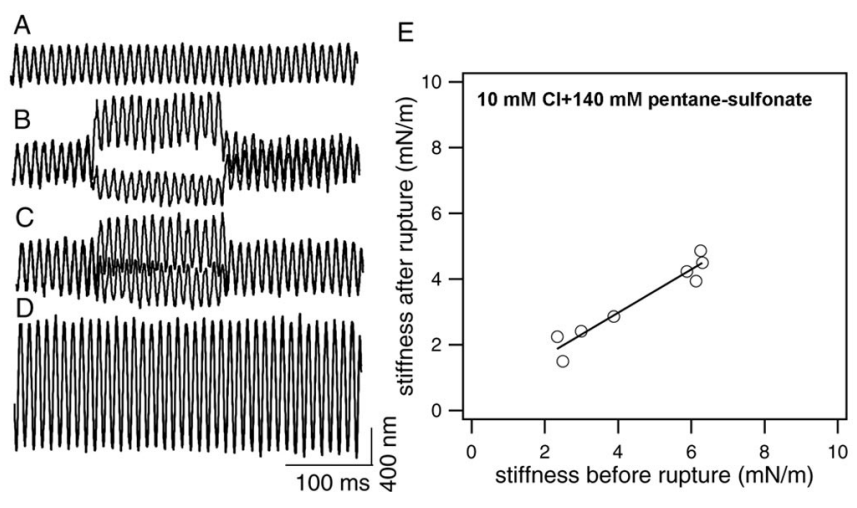

Figure 5. Stiffness changes with $10 \mathrm{~mm} \mathrm{Cl}{ }^{-}$in the patch pipette. $A$, Loaded fiber motion measured before the membrane of the cells was ruptured. $B$, Loaded fiber motion measured 30 sec after the membrane of the cells was ruptured. The patch pipette was filled with $10 \mathrm{~mm} \mathrm{KCl}$ and $140 \mathrm{~mm}$ sodium pentane sulfonate. C, Loaded fiber motion measured $2 \mathrm{~min}$ after the membrane of the cells was ruptured. The static stiffness of the cell measured before and after rupturing ( $2 \mathrm{~min}$ ) is 6.3 and $4.5 \mathrm{mN} / \mathrm{m}$, respectively. Fiber stiffness is $2.8 \mathrm{mN} / \mathrm{m}$. E, The stiffness measured from eight cells before and after rupture. The stiffness was reduced after the intracellular content was replaced by $10 \mathrm{~mm} \mathrm{Cl}^{-}$. The means of stiffness reduction is $24.6 \%$ with SD of $11.7 \%(n=8)$. Linear regression fit of the data yields a slope of 0.66 .

increase in stiffness is apparently caused by the difference in membrane potential before and after rupturing the cells. The membrane potential of the isolated cells was estimated to be between -15 and $-35 \mathrm{mV}$ (Ashmore and Meech, 1986; Dallos et al., 1997). After the membrane was ruptured, the membrane potential was forced to a holding potential of $-70 \mathrm{mV}$. Hyperpolarization from the initial resting potential should increase the stiffness of the cells (He and Dallos, 1999, 2000). For the cells shown in the right panel, their intracellular $\mathrm{Cl}^{-}$was replaced by pentane sulfonate. Neither motility nor voltage-dependent stiffness was observed for any cell in this group. The stiffness after rupturing the membrane of the cells was reduced significantly (the mean reduction was $54 \%$, with SD of $12 \%$ in 20 cells) with reference to the initial stiffness.

Previous work showed that the concentration required for half-maximal charge movement was $6.3 \mathrm{~mm}$ intracellular $\mathrm{Cl}^{-}$ (Oliver et al., 2001). We wanted to compare cell stiffness with approximately half-activating $\mathrm{Cl}^{-}$, but in the presence of pentane sulfonate, with the no chloride condition. To this end, stiffness changes were measured when $10 \mathrm{ml} \mathrm{Cl}^{-}$was applied intracellularly $(10 \mathrm{~mm} \mathrm{KCl}$ and $140 \mathrm{~mm}$ sodium pentane sulfonate in the patch pipettes). An example of such recording is illustrated in the left panels of Figure 5. The fiber-driven response was measured before the membrane of the cell was ruptured (Fig. $5 A$ ), and at $30 \mathrm{sec}$ (Fig. 5B) and 2 min (Fig. 5C) after membrane rupture. Although the voltage-dependent stiffness change is evident in both responses after rupture, the motility-dependent and voltage-dependent stiffness change are further reduced in the response obtained after $2 \mathrm{~min}$ with reference to the response at 30 sec. Furthermore, the baseline response increases after rupture, with the $2 \mathrm{~min}$ response being the smallest. From the baseline responses, the static stiffness change was calculated. Figure $5 E$ summarizes the result of static stiffness change measured from eight cells. The mean of stiffness reduction is $24.6 \%$ with SD of $11.7 \%$. This value is approximately half of the $54 \%$ reduction seen in stiffness change after intracellular $\mathrm{Cl}^{-}$was fully eliminated.
$150 \mathrm{mM} \mathrm{Cl}^{-}$

$150 \mathrm{mM}$ pentane-sulfonate ${ }^{-}$

A

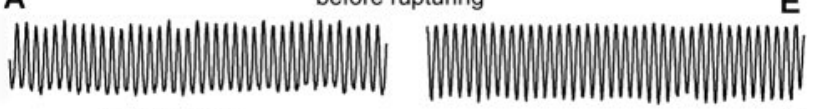

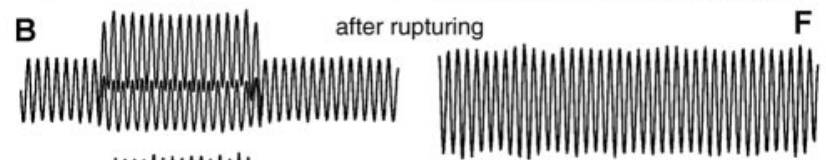
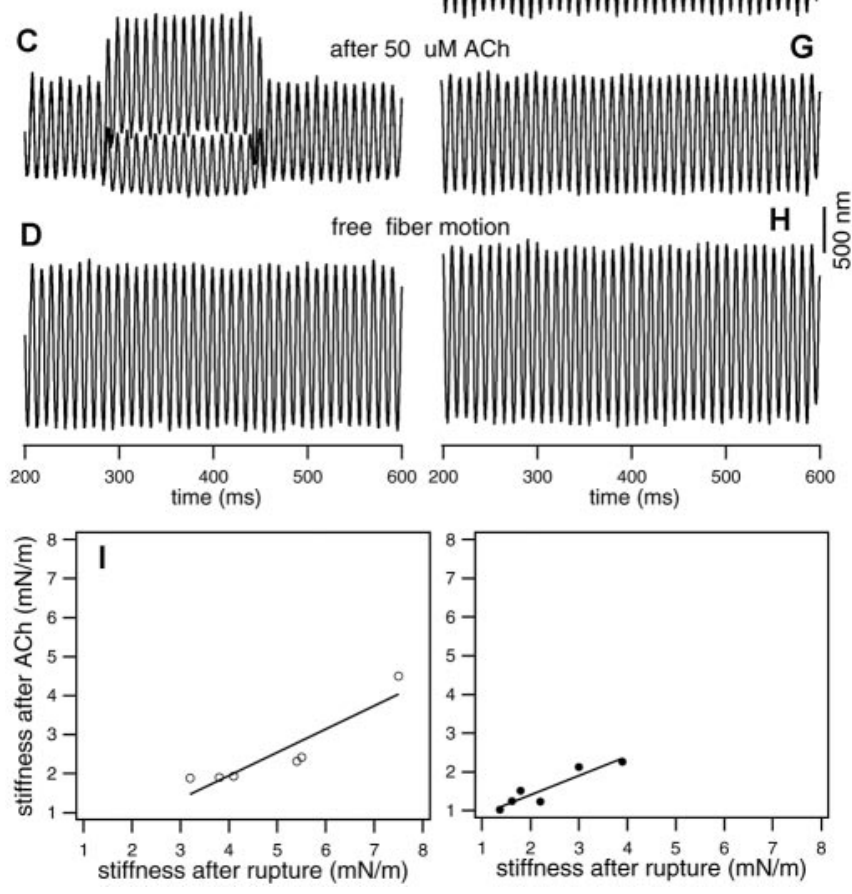

Figure 6. Effect of ACh on somatic motility and axial stiffness. The responses shown in the left panels were taken from an $\mathrm{OHC}$ with normal intracellular medium $\left(150 \mathrm{~mm} \mathrm{Cl}^{-}\right)$, whereas the responses on the right panels were from an $\mathrm{OHC}$ with $150 \mathrm{~mm}$ pentane sulfonate in the intracellular solution. $A$ and $E$ are loaded fiber motions measured before the membrane of the cells was ruptured. $B$ and $F$ are loaded fiber motions measured at $2 \mathrm{~min}$ after rupturing the membrane of the cells by the patch pipettes. ( and $G$ show loaded fiber motions obtained at 2 min after $50 \mu \mathrm{m}$ ACh was puffed to the synapse via a small pipette positioned near the synaptic area of the $\mathrm{OHCs}$. $D$ and $H$ are free fiber motions. Note that baseline responses increase in both cases after ACh application, as do responses evoked during electrical stimulation (left panels). The stiffness for the two cells is $4.15 \mathrm{mN} / \mathrm{m}$ (left panels; fiber stiffness: $3.1 \mathrm{mN} / \mathrm{m}$ ) and 4.05 $\mathrm{mN} / \mathrm{m}$ (right panels, fiber stiffness: $3.1 \mathrm{mN} / \mathrm{m}$ ), respectively. I, Stiffness change before and after applying $50 \mu \mathrm{m}$ ACh. Stiffness after rupture is used as reference. ACh was applied after the membrane was ruptured. ACh produced an average stiffness decrease of $52 \%$ with SD of $8 \%$ for the control group, whereas for the cells with no Cl, the mean reduction in stiffness is $28 \%$ with SD of $11 \%$. Line regression fit of the data yields slopes of 0.6 and 0.48 for the $\mathrm{Cl}^{-}$and pentane sulfonate groups, respectively.

\section{Effects of ACh on the stiffness of the motor protein and the cytoskeleton}

It has been demonstrated that ACh can modulate motility and axial stiffness of OHCs (Dallos et al., 1997). To determine whether ACh modulates motility and axial stiffness by altering the stiffness of the cortical lattice, experiments were performed on OHCs after their motility and voltage-dependent stiffness were abolished by removal of intracellular $\mathrm{Cl}^{-}$. Control experiments were also performed on OHCs with normal intracellular solution to determine whether an additional mechanism (modulation of the stiffness of the motor protein) is needed to account for the totality of ACh-induced motility and stiffness changes. In Figure 6, the results of the effects of ACh on the axial stiffness of two representative cells from the control (with $\mathrm{Cl}^{-}$) and experi- 
mental (without $\mathrm{Cl}^{-}$) groups are shown. In the left panels, the responses were obtained from an $\mathrm{OHC}$ with normal intracellular solution (150 mM KCl). Robust motility (Fig. 6 B, DC shift) and voltage-dependent stiffness change were observed. After $50 \mu \mathrm{M}$ ACh was applied, the amplitude of loaded motility significantly increased (Fig. 6C, DC shift). The amplitude of fiber-driven motion (Fig. 6C) also increased significantly with reference to the pre-ACh response shown in Figure $6 B$. The increase signifies that the stiffness of the cell was reduced after ACh application. In the right panels, measurements are shown from an $\mathrm{OHC}$ whose intracellular content was dialyzed with $150 \mathrm{~mm} \mathrm{Na-pentane} \mathrm{sulfo-}$ nate. It is apparent that motility and voltage-dependent stiffness are no longer present (Fig. $6 F$ ). The amplitude of fiber-driven response after rupture (Fig. $6 F$ ) is much greater than the reference response (Fig. $6 E$ ), because of the elimination of the voltagedependent stiffness component. Significantly, the stiffness of the cell is further reduced after ACh application. This is reflected by the amplitude increase of the fiber-driven response shown in Figure $6 G$. With the known stiffness of the fibers, and the availability of the amplitudes of fiber-driven response and free-fiber motion, we computed the stiffness changes for the two cells in response to ACh shown in Figure 6. On application of ACh, the stiffness decreased by $57 \%$, and the loaded motility increased by $58 \%$ for the cell having intracellular $\mathrm{Cl}^{-}$. For the cell in which the voltage-dependent component was eliminated $\left(\mathrm{no} \mathrm{Cl}^{-}\right.$), the reduction in stiffness was only $16 \%$. This reduction probably originated in changes associated with the other lateral wall structures such as the cortical lattice. We measured six cells with normal intracellular solution and six cells with $150 \mathrm{~mm}$ intracellular pentane sulfonate with the same fiber having a stiffness of $3.1 \mathrm{mN} / \mathrm{m}$. The result from the two groups is summarized in the bottom panels of Figure 6. After application of ACh, the average stiffness decreased by $52 \%$ with SD of $8 \%$ for the control group, whereas for the cells with no $\mathrm{Cl}$, the mean reduction in stiffness is $28 \%$ with SD of $11 \%$. It is thus likely that ACh affects both the motor proteins and the cytoskeleton of the lateral wall; this contention is elaborated in the Discussion.

\section{Discussion}

\section{Voltage-dependent stiffness and motility arise from the same mechanism}

By measuring the amplitude of driven vibrations of a fiber that was loaded by an isolated $\mathrm{OHC}$ while the cell was electrically stimulated under whole-cell voltage-clamp, it was shown that the amplitude of fiber motion was significantly modulated during the contraction-elongation cycle (electromotility: Brownell et al., 1985) of the cell. The finding is interpreted as a voltagedependent axial stiffness change of OHCs (He and Dallos, 1999). The voltage-dependent stiffness and voltage-dependent cell length are clearly related; several such relationships were revealed in a previous study (He and Dallos, 2000). These include the similar dependence of stiffness and length change on the command voltage, which is best fit by a Boltzmann process. Also, the same dependence of stiffness and length changes on electrical frequency and the reduction of both motility and voltagedependent stiffness by external application of $\mathrm{Gd}^{3+}$. Perhaps, the most suggestive relationship is the same dependence on intracellular $\mathrm{Cl}^{-}$of both motility and voltage-dependent stiffness, as shown in this study: elimination of intracellular $\mathrm{Cl}^{-}$abolishes both motility and voltage-dependent stiffness (Fig. 2). The general covariance of stiffness and length changes suggests that they may arise from a common mechanism, the motor protein. Existing standard models of $\mathrm{OHC}$ electromotility do not automati- cally yield stiffness changes of the type that we routinely observe (Iwasa, 2000). Two generic models (Dallos and He, 2000) have been proposed to explain both phenomena via a single mechanism. The first model assumes that molecular motors change both their axial dimension and stiffness on a voltage-dependent conformational shift. In the second model, only a stiffness change is associated with elementary motors. Corresponding cell length change is obtained if the quiescent cell is preloaded so that in its resting state it is shorter than its natural length. This model suggests that motility may simply be a consequence of stiffness change. This would then render voltage-dependent stiffness the primary mechanism, with length change being an epiphenomenon (He and Dallos, 1999).

\section{Voltage-dependent stiffness is a major contributor to the overall axial stiffness}

The present study shows that the average axial stiffness of the cells drops to $\sim 46 \%$ when the voltage-dependent stiffness is eliminated (represented in Fig. 4) because of the removal of intracellular chloride. The stiffness change is apparently dependent on intracellular $\mathrm{Cl}^{-}$concentration; $10 \mathrm{mM} \mathrm{Cl}^{-}$produces smaller stiffness reduction (25\% reduction as opposed to $54 \%$ decrease with no intracellular $\mathrm{Cl}^{-}$). Our results suggest that the plasma membrane, which contains the motor proteins, is a significant contributor to the stiffness of the composite lateral wall of the $\mathrm{OHC}$. We note that the $54 \%$ average reduction of axial stiffness is caused only by the reduction in stiffness attributable to the voltage-dependent component of the motor. The parallel cytoskeletal stiffness is presumably unaltered by the removal of chloride. Our result is consistent with the conclusions of Holley and Ashmore (1988), who found that it took significantly more force to compress the healthy cell than the demembranated cell (i.e., the remaining cortical lattice shell) in the axial direction. They suggested that the majority of lateral wall stiffness is inherent to the plasma membrane. Tolomeo et al. (1996) also used the technique of Triton X-100 demembranation to determine the stiffness of the cortical lattice, with similar conclusions. Using the microchamber technique, Russell and Schauz (1995) also showed that axial stiffness and electromotile forces were reduced by $65 \%$ when $5 \mathrm{~mm}$ salicylate was applied to the cell. Because salicylate blocks motility by competing with intracellular monovalent anions at the anion-binding site on the prestin molecule (Oliver et al., 2001), their finding is consistent with the conclusion of this study. However, these results contrast with the finding of Oghalai et al. (1998), who studied the interactions among the three cell wall layers with the micropipette aspiration technique. In their study, the plasma membrane was tethered to the cortical lattice and subsurface cisternae until, at a critical deformation pressure, the plasma membrane separated. After detaching, they found that the stiffness parameter of the plasma membrane was $22 \%$ of that of the intact lateral wall. Kalinec et al. (1992) found that, after intracellular perfusion of trypsin in OHCs to disrupt the cortical lattice and subsurface cisternae, the normal cylindrical shape was greatly altered such that the cell became more spherical. Both of these findings might appear to suggest that the cytoskeletal complex is primarily responsible for lateral wall stiffness. It is important to point out, however, that the stiffness measured from the tethering experiments using micropipette technique was in fact the bending stiffness of the cell membrane and only tenuously related to the axial stiffness of the cell. The assumption of spherical shape by the cell after disruption of the cortical lattice, is not surprising, because the cylindrical shape of intact OHCs is primarily dependent on the circumferential stiffness of the cortical 
lattice, which is reported to be much higher than its longitudinal stiffness (Holley and Ashmore, 1988, 1990).

Our conclusion is consistent with the view that the stiffness of the plasma membrane should be a significant component of the axial stiffness of the whole cell. Functionally, the stiffness of the plasma membrane must be at least within the same order of magnitude as that of the rest of the cell cortex. If it were not sufficiently stiff, most of the energy associated with conformational change of the motor protein would be stored in the plasma membrane itself as strain energy, whereas the stiffer cell cortex resisted the deformation. With the plasma membrane dominating the lateral wall stiffness, one hypothesis to explain $\mathrm{OHC}$ force coupling is the cytoskeletal spring model proposed by Holley and Ashmore (1990). An alternative possibility, suggested by Iwasa (1994) and further discussed by Tolomeo et al. (1996), is that motors in the plasma membrane transmit their force with the aid of the "pillars" to the cortical lattice, which then orients the forces in the axial direction.

We should comment on the use of pentane sulfonate as a means of replacing intracellular chloride (Oliver et al., 2001). Recently Rybalchenko and Santos-Sacchi (2003) suggested that effects seen on motility and nonlinear capacitance of outer hair cells when pentane sulfonate is substituted for $\mathrm{Cl}^{-}$, "is not due to manipulation of intracellular $\mathrm{Cl}^{-}$, but instead results from its direct action on the $\mathrm{OHC}$ motor." They suggest that the effects seen are a consequence of the depression of the voltage sensitivity of the motor by pentane sulfonate. This conclusion is contrary to that of Oliver et al. (2001) and is not consistent with the present results. Our data showing that approximately half-activating concentration of intracellular chloride, in the presence of $140 \mathrm{mM}$ pentane sulfonate, produced $\sim 50 \%$ response change, argues against the contention of Rybalchenko and Santos-Sacchi (2003). If pentane sulfonate would indeed depress the voltage sensitivity of prestin, it is unlikely that $10 \mathrm{mM} \mathrm{Cl}^{-}$could elicit a significant response in the presence of $140 \mathrm{~mm}$ pentane sulfonate as we see in Figure 5.

\section{ACh modulates stiffness of both the motor protein and the cytoskeleton}

Effects of ACh on OHC motility were studied by a number of investigators (Sziklai et al., 1996; Dallos et al., 1997; Kalinec et al., 2000). Dallos et al. (1997) suggested that the principal cause of increased electromotile response was a decreased global axial stiffness of the OHC. In other words, the aggregate of molecular motors that drive motility work against a smaller load in the presence of $\mathrm{ACh}$ and thereby produces larger cell excursion for a given electrical stimulus. We demonstrate here that the average axial stiffness of the cell is reduced by $52 \%$ in response to ACh treatment alone. When cells lacking internal $\mathrm{Cl}^{-}$were subjected to ACh, their average stiffness reduction is $28 \%$.

The cytoskeleton is regulated by the polymerization state of its filaments, which results in changes in mechanical properties of the cells. Recent evidence has shown that this regulation is accomplished in virtually all eukaryotic cells by a subfamily of proteins known as the Rho GTPases (Hall and Nobes, 2000). Colocalization of the small GTPases involved in regulating cytoskeletal proteins with the F-actin domains of the OHCs has been demonstrated (Kalinec et al., 2000). These investigators showed that the intracellular signaling pathways involving the small GTPases RhoA, Rac1, and Cdc42 regulate the response of the OHCs to ACh. Calcium as a second messenger to mediate ACh effect on motility and stiffness has also been proposed ( $\mathrm{Mu}-$ rugasu and Russell, 1996; Sridhar et al., 1997). Previous demon- stration of calcium release from internal stores, with a time course similar to the "slow" efferent effects, suggests the possibility that the global stiffness decrease is somehow tied to either decreased sequestered $\mathrm{Ca}^{2+}$ levels in the cisternal region or to an increased level of cytosolic calcium (Dallos et al., 1997). A possible target is the primarily axial spectrin links between adjacent circumferential actin filaments in the cortical lattice.

If ACh affected only the cytoskeleton and internal chloride only the motor, we could formulate a simple model for the additivity of constituent stiffnesses. Accordingly, $K_{\text {cell }}=K_{\text {mot }}{ }^{\text {res }}+$ $K_{\text {cyt }}{ }^{\text {res }}+K_{\text {mot }}{ }^{\mathrm{Cl}}+K_{\text {cyt }}{ }^{\mathrm{ACh}}$, where the subscripts refer to motorrelated or cytoskeleton-related stiffness components and the superscripts reflect ACh-controlled, chloride-controlled and residual stiffness components. Let us work with experimental results obtained from a representative cell whose axial stiffness is 4.15 $\mathrm{mN} / \mathrm{m}$. In the absence of $\mathrm{Cl}^{-}$, the measured stiffness is $2.01 \mathrm{mN} /$ $\mathrm{m}=K_{\mathrm{mot}}{ }^{\text {res }}+K_{\text {cyt }}{ }^{\text {res }}+K_{\text {cyt }}{ }^{\text {ACh }}$. Consequently, the motor stiffness component controlled by chloride (i.e., the voltagedependent component) is $K_{\text {mot }}{ }^{\mathrm{Cl}}=2.14 \mathrm{mN} / \mathrm{m}$. Conversely, we find that in the presence of ACh the cell stiffness is $2.14 \mathrm{mN} / \mathrm{m}=$ $K_{\text {mot }}{ }^{\text {res }}+K_{\text {cyt }}{ }^{\text {res }}+K_{\text {mot }}{ }^{\mathrm{Cl}}$. From this we compute the AChdependent stiffness of the cytoskeleton to be: $K_{\text {cyt }}{ }^{\mathrm{ACh}}=2.01$ $\mathrm{mN} / \mathrm{m}$. When we apply ACh to a cell with no internal chloride, we measure $K_{\text {mot }}{ }^{\text {res }}+K_{\text {cyt }}{ }^{\text {res }}=1.15 \mathrm{mN} / \mathrm{m}$. Assuming independence and adding all these computed values yields a total stiffness ( 5.3 $\mathrm{mN} / \mathrm{m})$ that is greater than the control value $(4.15 \mathrm{mN} / \mathrm{m})$; clearly not a possible outcome. This exercise suggests that the assumption of separability is wrong and mandates that ACh action affects both the motor and the cytoskeleton. The caveat going with the previous statement is that we are not aware of information that would suggest that cytoskeletal elements are chloride-sensitive.

It is very likely that ACh influences the motor protein itself through protein phosphorylation. Some protein phosphorylation inhibitors and activators have been shown to affect electromotility and nonlinear capacitance of OHCs (Szönyi et al., 1999a,b; Frolenkov et al., 2000, 2003). There are several positions on the prestin molecule that are potential cGMP-dependent protein kinase and PKC phosphorylation sites. Some preliminary studies have shown that delivery of a cGMP analog can significantly increase nonlinear, voltage-dependent charge displacement in prestin-transfected heterologous cells that have a cytoskeletal structure different than that of OHCs (Deak et al., 2003). Mutation of the appropriate phosphorylation sites eliminated the effect. Furthermore, mutation at some potential PKA phosphorylation sites of prestin shifted $V_{1 / 2}$ of the nonlinear capacitance curve (Oliver et al., 2001). Some PKC inhibitors also shifted the $V_{1 / 2}$ (Matsuda et al., 2003). All these observations support our conclusion that ACh, via a second messenger cascade, may also have an effect on the prestin motors themselves via protein phosphorylation.

\section{References}

Adachi M, Iwasa K (1997) Effect of diamide on force generation and axial stiffness of the cochlear outer hair cell. Biophys J 73:2809-2818.

Ashmore JF (1987) A fast motile response in guinea pig outer hair cells: the cellular basis of the cochlear amplifier. J Physiol (Lond) 388:323-347.

Ashmore JF, Meech RW (1986) Ionic basis of membrane potential in outer hair cells of guinea pig cochlea. Nature 322:368-371.

Brownell WE, Bader CR, Bertrand D, de Ribaupierre Y (1985) Evoked mechanical responses of isolated cochlear hair cells. Science 227:194-196.

Dallos P, He DZZ (2000) Two models of outer hair cell stiffness and motility. J Assoc Res Otolaryngol 1:283-291.

Dallos P, He DZZ, Lin X, Sziklai I, Mehta S, Evans BN (1997) Acetylcholine, 
outer hair cell electromotility, and the cochlear amplifier. J Neurosci 17:2212-2226.

Deak L, Zheng J, Matsuda K, Du GG, Dallos P (2003) Effects of cGMP on Prestin-transfected HEK cells. Abstracts of Mid-Winter Meeting of Assoc Res Otolaryngol, Abstract 408, Daytona Beach, FL, February.

Elgoyhen AB, Johnson DS, Boulter J, Vetter DE, Heinemann S (1994) $\alpha 9$ : An acetylcholine receptor with novel pharmacological properties expressed in rat cochlear hair cells. Cells 79:705-715.

Forge A (1991) Structural features of the lateral walls in mammalian cochlear outer hair cells. Cell Tissue Res 265:473-483.

Frolenkov GI, Mammano F, Belyantseva IA, Coling D, Kachar B (2000) Two distinct $\mathrm{Ca}^{2+}$-dependent signaling pathways regulate the motor output of cochlear outer hair cells. J Neurosci 20:5940-5948.

Frolenkov GI, Mammano F, Kachar B (2003) Regulation of outer hair cell cytoskeletal stiffness by intracellular $\mathrm{Ca}^{2+}$ : underlying mechanism and implications for cochlear mechanics. Cell Calcium 33:185-195.

Gitter AH, Rudert M, Zenner HP (1993) Forces involved in length changes of cochlear outer hair cells. Pflügers Arch 424:9-14.

Hall A, Nobes CD (2000) Rho GTPases: molecular switches that control the organization and dynamics of the actin cytoskeleton. Philos Trans R Soc Lond B Biol Sci 355:965-970.

Hallworth R (1995) Passive compliance and active force generation in the guinea pig outer hair cell. J Neurophysiol 74:2319-2328.

Hallworth R (1997) Modulation of outer hair cell compliance and force by agents that affect hearing. Hear Res 114:204-212.

He DZZ, Dallos P (1999) Somatic stiffness of cochlear outer hair cells is voltage-dependent. Proc Natl Acad Sci USA 96:8223-8228.

He DZZ, Dallos P (2000) Properties of voltage-dependent somatic stiffness of cochlear outer hair cells. J Assoc Res Otolaryngol 1:64-81.

Holley MC (1996) Outer hair cell motility. In: The cochlea (Dallos P, Popper AN, and Fay RR, eds), pp 386-434. New York: Springer.

Holley MC, Ashmore JF (1988) A cytoskeletal spring in cochlear outer hair cells. Nature 335:635-637.

Holley MC, Ashmore JF (1990) Spectrin, actin and the structure of the cortical lattice in mammalian cochlear outer hair cells. J Cell Sci 96:283-291.

Iwasa KH (1994) A membrane motor model for the fast motility of the outer hair cell. J Acoust Soc Am 96:2216-2224.

Iwasa KH (2000) Effect of membrane motor on the axial stiffness of the cochlear outer hair cell. J Acoust Soc Am 107:2764-2766.

Iwasa KH, Adachi M (1997) Force generation in the outer hair cells of the cochlea. Biophys J 73:546-555.

Kachar B, Brownell WE, Altschuler R, Fex J (1986) Electrokinetic shape changes of cochlear outer hair cells. Nature 322:365-368.

Kalinec F, Holley M, Iwasa K, Lim D, Kachar BA (1992) Membrane based force generation mechanism in auditory sensory cells. Proc Natl Acad Sci USA 89:8671-8675.

Kalinec F, Zhang M, Urrutia R, Kalinec G (2000) Rho GTPases mediate the regulation of cochlear outer hair cell motility by acetylcholine. J Biol Chem 275:28000-28005.

Liberman MC, Gao JG, He DZZ, Wu XD, Jia SP, Zuo J (2002) Prestin is required for electromotility of the outer hair cell and for the cochlear amplifier. Nature 419:300-304.

Matsuda K, Zheng J, Du GG, Deak L, Navarrete E, Dallos P (2003) Protein kinase $\mathrm{C}$ and voltage-dependent capacitance in Prestin-transfected TSA cells. Abstracts of Mid-Winter Meeting of Assoc Res Otolaryngol, Abstract 415, Daytona Beach, FL, February.

Murugasu E, Russell IJ (1996) The effect of efferent stimulation on basilar membrane displacement in the basal turn of the guinea pig cochlea. J Neurosci 16:325-332.

Oghalai JS, Patel AA, Nakagawa T, Brownell WE (1998) Fluorescenceimaged microdeformation of the outer hair cell lateral wall. J Neurosci 18:48-58.

Oliver D, He DZZ, Klőcker N, Ludwig J, Schulte U, Waldegger S, Ruppersberg JP, Dallos P, Fakler B (2001) Intracellular anions as the voltage-sensor of prestin, the outer hair cell motor protein. Science 292:2340-2343.

Russell I, Schauz C (1995) Salicylate ototoxicity: effects on the stiffness and electromotility of outer hair cells isolated from the guinea pig cochlea. Audit Neurosci 1:309-319.

Rybalchenko V, Santos-Sacchi J (2003) $\mathrm{Cl}^{-}$flux through non-selective, stretch-sensitive conductance influences the outer hair cell motor of the guinea pig. J Physiol (Lond) 547:873-891.

Sridhar TS, Brown MC, Sewell WF (1997) Unique postsynaptic signaling at the hair cell efferent synapse permits calcium to evoke changes on two time scales. J Neurosci 17:428-437.

Sziklai I, He DZZ, Dallos P (1996) Effect of acetylcholine and GABA on the transfer function of electromotility in isolated outer hair cells. Hear Res 95:87-99.

Szönyi M, He DZZ, Ribari O, Sziklai I, Dallos P (1999a) Cyclic GMP and outer hair cell electromotility. Hear Res 137:29-42.

Szönyi M, Csermely P, Sziklai I (1999b) Acetylcholine induced phosphorylation in isolated outer hair cells. Acta Otolaryngol (Stockh) 119:185-188.

Tolomeo JA, Steele CR, Holley MC (1996) Mechanical properties of the lateral cortex of mammalian auditory outer hair cells. Biophys J 71:421-429.

Ulfendahl M, Chan E, McConnaughey WB, Prost-Domasky S, Elson EL (1998) Axial and transverse stiffness measures of cochlear outer hair cells suggest a common mechanical basis. Pflügers Arch 436:9-15.

Zenner HP, Gitter AH, Rudert M, Ernst A (1992) Stiffness, compliance, elasticity and force generation of outer hair cells. Acta Otolaryngol (Stockh) 112:248-253.

Zheng J, Shen W, He DZZ Long KB, Madison LD, Dallos P (2000) Prestin is the motor protein of cochlear outer hair cells. Nature 405:149-155.

Zwislocki JJ, Cefaratti LK (1989) Tectorial membrane II: Stiffness measurements in vivo. Hear Res 42:211-228. 